\title{
Synaptogenesis Via Dendritic Filopodia in Developing Hippocampal Area CA1
}

\author{
John C. Fiala, ${ }^{1}$ Marcia Feinberg, ${ }^{1}$ Viktor Popov ${ }^{2}$, Kristen M. Harris ${ }^{1}$ \\ ${ }^{1}$ Division of Neuroscience in the Department of Neurology, Children's Hospital, Boston Massachusetts, and 2Institute of \\ Cell Biophysics, Russian Academy of Sciences, Pushchino, Moscow Region, 142292, Russia
}

To determine the role of dendritic filopodia in the genesis of excitatory synaptic contacts and dendritic spines in hippocampal area CA1, serial section electron microscopy and threedimensional analysis of 16 volumes of neuropil from nine male rat pups, aged postnatal day 1 (P1) through $\mathrm{P} 12$, were performed. The analysis revealed that numerous dendritic filopodia formed asymmetric synaptic contacts with axons and with filopodia extending from axons, especially during the first postnatal week. At P1, $22 \pm 5.5 \%$ of synapses occurred on dendritic filopodia, with $19 \pm 5.9 \%$ on filopodia at P4, $20 \pm 8.0 \%$ at P6, decreasing to $7.2 \pm 4.7 \%$ at P12 ( $p<0.02$ ). Synapses were found at the base and along the entire length of filopodia, with many filopodia exhibiting multiple synaptic contacts. In all, 162 completely traceable dendritic filopodia received 255 asymmetric synaptic contacts. These synapses were found at all parts of filopodia with equal frequency, usually occurring on fusiform swellings of the diameter. Most synaptic contacts (53 $\pm 11 \%)$ occurred directly on dendritic shafts during the first postnatal week. A smaller but still substantial portion (32 \pm $12 \%)$ of synapses were on shafts at P12 ( $p<0.036)$. There was a highly significant $(p<0.0002)$ increase in the proportion of dendritic spine synapses with age, rising from just $4.9 \pm 4.3 \%$ at $\mathrm{P} 1$ to $37 \pm 14 \%$ at $\mathrm{P} 12$. The concurrence of primarily shaft and filopodial synapses in the first postnatal week suggests that filopodia recruit shaft synapses that later give rise to spines through a process of outgrowth.

Key words: serial electron microscopy; postsynaptic density; synapse; rat; pyramidal cell; dendrites; spines; three-dimensional reconstructions
Most excitatory synapses in adult brain are located on the bulbous heads of dendritic spines (Harris and Kater, 1994). During development, before the expression of spines, cortical dendrites exhibit longer, thinner processes, often without a bulbous head (Purpura, 1975). These dendritic filopodia disappear, and spines appear as the cortex matures. This transition can be disrupted by developmental abnormalities that induce mental retardation, such as fetal alcohol syndrome (Purpura, 1975; Stoltenburg-Didinger and Spohr, 1983; Galofre et al., 1987). Dendrites from mentally retarded adults often appear to be covered with dendritic filopodia instead of spines (Marin-Padilla, 1972; Wisniewski et al., 1991). The significance of these findings is not entirely clear, partly because the role of dendritic filopodia in synapse and spine formation is uncertain.

Several recent in vitro studies have shown that filopodia are active along the lengths of dendrites during postnatal synaptogenesis in hippocampal area CA1. Confocal microscopy of dissociated hippocampal neurons from embryonic or neonatal rats revealed long, headless dendritic protrusions during the initial 1-2 weeks in culture (Papa et al., 1995; Ziv and Smith, 1996). These filopodia were remarkably transient structures, extending and retracting in $<10 \mathrm{~min}$ in some cases. Although some filopodia

\footnotetext{
Received June 8, 1998; revised Aug. 3, 1998; accepted Aug. 17, 1998.

This work was supported by National Institutes of Health Grants NS21184 and NS33574, Human Brain Project (HBP) Grant R01 MH/DA 57351 (K.M.H.) and Mental Retardation Research Center Grant P30-HD18655 (Dr. Joseph Volpe, PI). The HBP research is funded jointly by National Institute of Mental Health, National Institute on Drug Abuse, and NASA.

Correspondence should be addressed to Dr. Kristen M. Harris, Division of Neuroscience, Enders 260, Children's Hospital, 300 Longwood Avenue, Boston, MA 02115.

Copyright (ㄷ) 1998 Society for Neuroscience $\quad 0270-6474 / 98 / 188900-12 \$ 05.00 / 0$
}

made apparent synaptic contacts with axons (Ziv and Smith, 1996), ultrastructural examination found that the majority of filopodia at 1 week in culture had no synaptic contacts (Papa et al., 1995). Over a period of 4 weeks in culture, there was a transition from relatively sparse, yet dynamic filopodial protrusions, to a dense distribution of stable, adult-like spines. Similar results were obtained from area CA1 in hippocampal slice cultures (Dailey and Smith, 1996; Collin et al., 1997).

The appearance of filopodia before the formation of spines, and the fact that some filopodia retract into a more stable, spine-like shape has lead to the hypothesis that most spines form directly from filopodia (Ziv and Smith, 1996). This hypothesis posits that filopodia initiate synaptic contacts that mature into spine synapses. In older cultures, rapid extension of stable spines directly from the dendrite shafts was observed without the prior appearance of dynamic filopodia (Dailey and Smith, 1996). This suggests that spines can arise from shaft synapses and is consistent with ultrastructural data showing that synapses occur primarily on dendritic shafts and stubby spines before postnatal day 15 (P15), with a subsequent transition to most synapses on longer thin spines in the young adult rat (Schwartz et al., 1968; Cotman et al., 1973; Miller and Peters, 1981; Porkorny and Yamamoto, 1981; Schwartzkroin et al., 1982; Steward and Falk, 1991; Harris et al., 1992).

To determine whether dendritic filopodia make synaptic contacts and whether filopodia could be involved in the production of shaft synapses, we conducted a serial electron microscopy analysis of in vivo development of synaptic contacts in area CA1. Volumetric analyses were used to identify the three-dimensional structures (dendrites, spines, and filopodia) on which synapses occurred. The results show that filopodial synapses develop 
Table 1. Location, volume, and number of synapses for each set of serial section electron micrographs. $R$ numbers are individual rat numbers for a total of nine rats; letters $a, b$, and $c$ are the specific series identifiers

\begin{tabular}{|c|c|c|c|c|c|c|c|c|c|}
\hline Series & Age & $\begin{array}{l}\text { Total width of } \\
\text { apical arbor } \\
\text { (micrometers) }\end{array}$ & $\begin{array}{l}\text { Series location } \\
\text { (micrometers from } \\
\text { cell body layer) }\end{array}$ & $\begin{array}{l}\text { Volume analyzed } \\
\text { (cubic micrometers) }\end{array}$ & $\begin{array}{l}\text { Total number } \\
\text { of synapses }\end{array}$ & $\begin{array}{l}\text { Number of } \\
\text { filopodia synapses }\end{array}$ & $\begin{array}{l}\text { Number of } \\
\text { shaft synapses }\end{array}$ & $\begin{array}{l}\text { Number of } \\
\text { stubby synapses }\end{array}$ & $\begin{array}{l}\text { Number of } \\
\text { spine synapses }\end{array}$ \\
\hline R52a & PN1 & 165 & 100 & 346.22 & 64 & 9 & 41 & 5 & 4 \\
\hline R52b & PN1 & 165 & 130 & 1066.41 & 116 & 25 & 76 & 6 & 2 \\
\hline R53 & PN1 & 160 & 20 & 781.38 & 97 & 24 & 42 & 22 & 1 \\
\hline R55 & PN1 & 140 & 125 & 391.04 & 50 & 13 & 22 & 6 & 5 \\
\hline R48a & PN4 & 200 & 100 & 482.17 & 80 & 18 & 46 & 5 & 3 \\
\hline $\mathrm{R} 48 \mathrm{~b}$ & PN4 & 200 & 100 & 332.81 & 51 & 8 & 31 & 5 & 2 \\
\hline R60a & PN4 & 250 & 115 & 638.12 & 90 & 11 & 45 & 15 & 7 \\
\hline R60b & PN4 & 250 & 115 & 573.78 & 109 & 27 & 58 & 16 & 2 \\
\hline R43a & PN6 & 300 & 265 & 270.92 & 120 & 33 & 54 & 8 & 17 \\
\hline $\mathrm{R} 43 \mathrm{~b}$ & PN6 & 300 & 265 & 200.96 & 103 & 10 & 58 & 5 & 17 \\
\hline R44a & PN6 & 275 & 40 & 553.87 & 118 & 17 & 53 & 14 & 17 \\
\hline $\mathrm{R} 44 \mathrm{~b}$ & PN6 & 275 & 115 & 610.48 & 114 & 27 & 31 & 25 & 27 \\
\hline R45a & PN12 & 300 & 266 & 77.06 & 107 & 12 & 25 & 16 & 45 \\
\hline $\mathrm{R} 45 \mathrm{~b}$ & PN12 & 300 & 266 & 122.27 & 99 & 10 & 18 & 12 & 48 \\
\hline $\mathrm{R} 47 \mathrm{~b}$ & PN12 & 400 & 180 & 85.33 & 105 & 3 & 47 & 18 & 33 \\
\hline R47c & PN12 & 400 & 180 & 60.54 & 60 & 2 & 23 & 20 & 12 \\
\hline
\end{tabular}

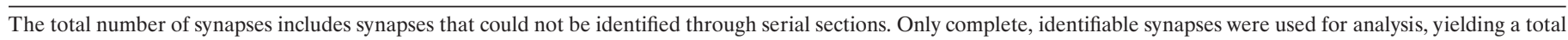
of 1417 for all ages.

concomitantly with an abundance of shaft synapses, before spine formation. The data support a role for filopodia in the genesis of shaft synapses, which later develop into dendritic spines.

\section{MATERIALS AND METHODS}

Animals. Nine male rat pups of the Long-Evans strain at four different ages were used (Table 1). Three animals were from P1, and two each were from P4, P6, and P12. Our procedures follow National Institutes of Health guidelines and undergo yearly review by the Animal Care and Use Committee at Children's Hospital.

Tissue preparation and microscopy. Animals were perfused through the heart under deep $(80 \mathrm{mg} / \mathrm{kg})$ pentobarbital anesthesia with $2.5 \%$ glutaraldehyde, $2 \%$ paraformaldehyde, $2 \mathrm{mM} \mathrm{CaCl}_{2}$, and $4 \mathrm{mM} \mathrm{MgCl}_{2}$ in $0.1 \mathrm{M}$ cacodylate buffer. Whole brains were removed after $1 \mathrm{hr}$ and post-fixed overnight in the same fixative. The next day the brain was rinsed in buffer and sliced into $300 \mu \mathrm{m}$ slabs, from which the hippocampus with dentate gyrus was dissected.

Routine processing of the hippocampi for electron microscopy (EM) was accelerated using the PELCO 3450 laboratory microwave processor (Ted Pella Inc., Redding, CA). A slab of hippocampus was placed in an individual microcentrifuge tube with $1 \%$ osmium and $1.5 \%$ potassium ferrocyanide in $0.1 \mathrm{M}$ cacodylate buffer solution, cooled in an ice bath to $<15^{\circ} \mathrm{C}$, then microwaved for $2.5 \mathrm{~min}$ at $37^{\circ} \mathrm{C}$. After several buffer rinses, a second stage osmium solution ( $1 \%$ osmium in $0.1 \mathrm{M}$ cacodylate buffer) was added, cooled to $<15^{\circ} \mathrm{C}$, and then microwaved again for $2.5 \mathrm{~min}$ at $37^{\circ} \mathrm{C}$. The tissue was rinsed several times in buffer followed by two brief water rinses and then a $1 \%$ aqueous uranyl acetate was added for en bloc staining. This solution was also cooled to $<15^{\circ} \mathrm{C}$ and then microwaved for $2.5 \mathrm{~min}$ at $37^{\circ} \mathrm{C}$, followed by two brief water rinses and then dehydrated through graded acetones beginning with 50\%, then 70, 90, and $100 \%$ exchanges in the microwave at $45^{\circ} \mathrm{C}, 40 \mathrm{sec}$ each exchange. The dehydrated tissue was infiltrated in the microwave using acetone mixed with 1:1 Epon and Spurr's resin mixtures for $15 \mathrm{~min}$ at $50^{\circ} \mathrm{C}$. This was followed by two changes of fresh $100 \%$ Epon/Spurr's for 15 min each at $50^{\circ} \mathrm{C}$. For final polymerization and curing the tissue was transferred to BEEM embedding capsules. Some tissue was cured in the microwave and others were cured in a $60^{\circ} \mathrm{C}$ conventional oven for $48 \mathrm{hr}$.

The cured blocks were cut with a diamond Histo knife on a Reichart Ultracut S (Leica, Allendale, NJ) ultramicrotome to obtain a full-face section ( $1 \mu \mathrm{m}$ thickness) of the hippocampus and dentate gyrus. These were stained with $1 \%$ toluidine blue and examined under light microscopy. A trapezoid, $30-115 \mu \mathrm{m}$ in height and $50-115 \mu \mathrm{m}$ base width, was cut from the apical dendritic field of area CA1 using a Diatome squareshaped trim tool (Electron Microscopy Sciences, Fort Washington, PA).
Table 1 gives the location of each trapezoid, illustrating how both proximal and distal portions of the apical field were sampled at each age.

Serial sections were made from the trimmed blocks with silver to platinum coloring (nominally $70 \mathrm{~nm}$ ). The number of sections varied from 52 to 135 for each of the 16 series. Series were mounted on Synaptek pioloform-coated slot grids (Ted Pella Inc.) and stained with saturated ethanolic uranyl acetate, followed by Reynold's lead citrate, each for $5 \mathrm{~min}$. Each grid was then loaded into a grid cassette (Advanced Microscopy Techniques, Danvers, MA) and stored in numbered gelatin capsules (Ernest Fullam Inc., Latham, NY). The grid cassettes were mounted in rotating stages to obtain consistent orientation of sections on adjacent grids during photography at a JEOL (Peabody, MA) 1200EX electron microscope. Each series was photographed at $6000 \times$ magnification along with a corresponding calibration grid $(0.463 \mu \mathrm{m}$ per square, Ernest Fullam Inc.) and printed at $16000 \times$ magnification on $8.5 \times 11$ inch paper.

Analysis. A volume of tissue was analyzed from the middle of each series of micrographs so that neuronal structures (synapses, axons, dendrites, spines, and filopodia) could be traced through the series and identified by three-dimensional (3D) structure (Table 1). Each micrograph in the volume was systematically scanned for synapses. Asymmetric synapses were identified by the presence of a postsynaptic density (PSD) and at least two presynaptic clear vesicles $30-40 \mathrm{~nm}$ in diameter in close proximity to the PSD. En face sections of PSDs were included when vesicles were found on an adjacent section. In some instances membrane densities were observed at points of close apposition in the absence of synaptic vesicles. These were classified as nonsynaptic surface specializations rather than as synapses. Symmetrical synapses were differentiated from asymmetrical ones by thinner densities on both sides of the synapse. Once a synapse was identified, the postsynaptic process was traced through the series to identify the location of the synapse as dendritic shaft, stubby, spine, or filopodium. No attempt was made to differentiate synapses on aspiny interneurons from those on pyramidal neurons because it is difficult to distinguish these cell types at these early ages (see Discussion).

A shaft synapse was one that occurred on the surface of a dendrite. The dendrite was differentiated from spines and filopodia by a less densely stained cytoplasm that contained microtubules and mitochondria. The nature of the dendrite at the synapse location was further characterized as either thin, varicose, or apical-like. Apical-like dendrites were ones with a large cross-section (i.e., $>1 \mu \mathrm{m}$ diameter) and a well organized array of microtubules. Other dendrites exhibited a nonuniform cross-section in which varicose regions, enlargements with a watery cytoplasm and very sparse or disorganized microtubules, were inter- 
Figure 1. Representative CA1 neuropil from postnatal day 1 (R53) has large amounts of extracellular space $(E C S)$. A dendrite $(D)$ with well organized microtubules gives rise to a dendritic filopodium $(d f)$, which continues on adjacent serial sections. An asymmetric synapse $(s)$ on a stubby dendritic protrusion is evident at the top of the figure. Also in evidence are nonsynaptic surface specializations (solid square arrows). The tip of an axonal filopodium (af), identified by tracing it back to its axonal origin, has a surface specialization or possibly a nascent synapse (open arrow) where it contacts the tip of a dendritic filopodium $(f)$, also identified through series. Scale bar, $1 \mu \mathrm{m}$.

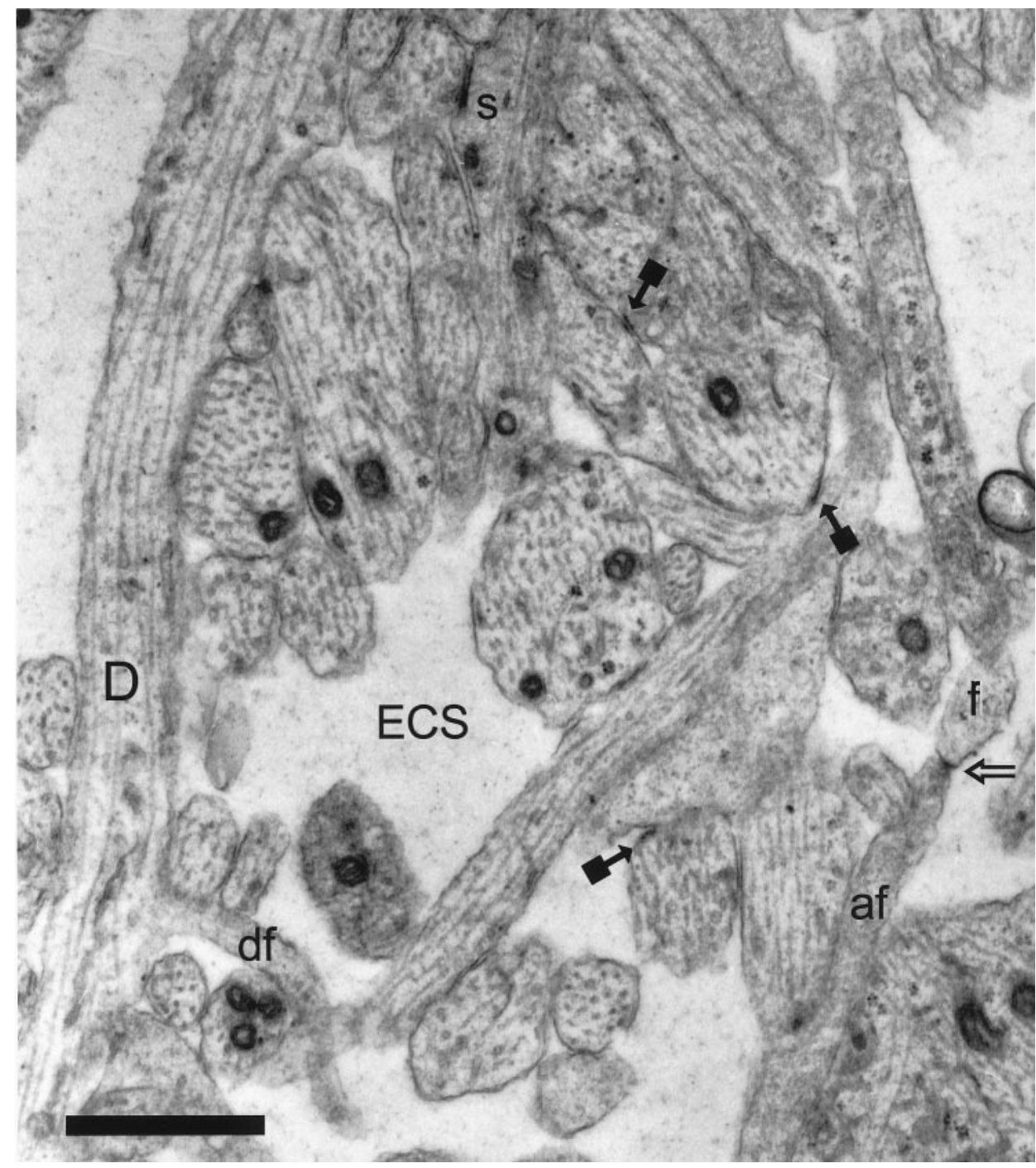

spersed with thin regions that were microtubule-dense and of much smaller diameter.

A stubby synapse occurred on a short (length less than width) protrusion of the surface of the dendrite without a constricted neck region. The protrusion was devoid of microtubules and contained a grainy appearance, typically darker than the adjacent dendritic cytoplasm. Sometimes these stubby protrusions had features uncharacteristic of more mature material (Harris et al., 1992), such as having a pointy tip with a small synapse at the tip or a large synapse at the base, or having multiple synapses. Such synapses were classified as atypical stubby synapses.

A spine synapse was one that occurred at the swollen tip (head) of a relatively short $(<2 \mu \mathrm{m})$ protrusion separated from the dendrite by a constricted neck region. Criteria for spine classification were the same as in previous studies (Peters and Kaiserman-Abramof, 1970; Harris et al., 1992), however, some spines exhibited characteristics that were not typical of spines in area CA1 of the adult. These unusual characteristics included having multiple synapses on the head, having an additional asymmetrical synapse at the base or neck, having a very dark, grainy cytoplasm, having multiple branches, and having an abnormal neck morphology (e.g., too small, $<80 \mathrm{~nm}$, or with a swelling in the middle). Synapses occurring on these processes were classified as atypical spine synapses. Short emerging or retracting filopodia, when present, were probably placed into an atypical category.

Filopodia synapses occurred on dendritic protrusions that were nonspine-like, i.e., not having a single bulbous head on a narrower stalk. Filopodia were distinguished from stubbies and spines by having greater length and/or a pointy, rather than a bulbous tip. Sometimes filopodia could be identified by having a very narrow or variable cross-sectional area or having synaptic contacts distributed along their length. A synapse on a filopodium was further classified as being at a tip, mid, or base location. A tip synapse occurred at the filopodium tip or on a swelling in continuity with the tip. A base synapse was located on the dendritic shaft at the origin of the filopodium or on an enlargement of the filopodium in continuity with the shaft. A mid synapse was located at any location along the filopodium between its tip and base.

A final category of synapse location was on a growth cone or lamellipodium. Growth cones and lamellipodia were identified by a grainy, microtubule-free cytoplasm, often filled with large vesicular compartments. Unlike filopodia, these structures were not narrow cylindrical processes protruding from a dendrite. They had a complex threedimensional structure much larger than filopodia, often in the form of a flattened sheet.

A continuous volume of tissue containing 50-120 synapses was examined from the middle of each series in a systematic section-by-section analysis. Synapses were identified and traced through the series so that they were only counted once. If the process on which a synapse occurred did not contain microtubules, it was traced through the series to its tip and origin. The origins of these processes could usually be traced to a main shaft that did contain microtubules. The shaft of origin could be a dendrite or an axon, identified by determining if it was postsynaptic or presynaptic to a synapse located somewhere along its length. If the origin could not be identified, then the synapse was not included in the analyses of synapse types. ANOVA were computed using Statistica software (StatSoft Inc., Tulsa, OK).

Reconstructions. To obtain 3D reconstructions and measurements from the tissue, micrographs were digitized using a Hewlett-Packard (Palo Alto, CA) ScanJet 4c flatbed scanner. Serial sections were then aligned on a Windows NT (Microsoft, Redmond, WA) personal computer using 


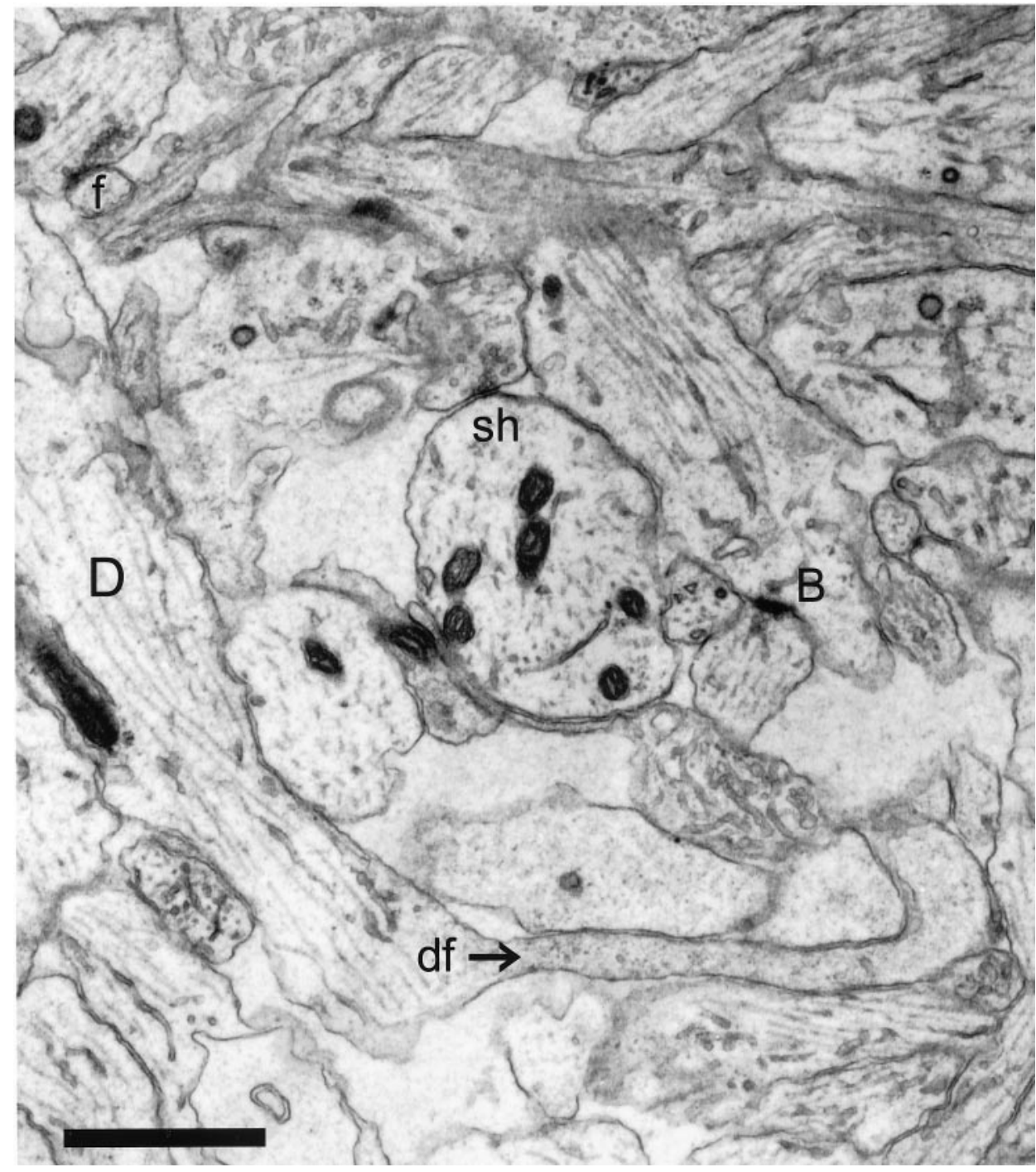

Figure 2. Representative CA1 neuropil from postnatal day 4 (R48a). A dendritic filopodium $(d f)$ emerges from the middle of a dendrite $(D)$. The entire filopodium is reconstructed in Figure 5. A synapse on an apparently stubby profile is actually at the base $(B)$ of a filopodium that could be traced on adjacent serial sections. A shaft synapse $(s h)$ has synaptic vesicles in a docked position, suggesting the synapse is functional. The profile in the upper left corner $(f)$ makes synaptic contact with an axon containing docked vesicles. This synapse occurs in the middle of a dendritic filopodium that could be followed for 70 sections to its tip, at which there was no synaptic contact. Scale bar, $1 \mu \mathrm{m}$.
IGL Align, developed by JCF in the Image Graphics Laboratory (IGL) of the Mental Retardation Research Center at Children's Hospital. The magnification of each digitized series was calibrated using the standard grid that was imaged with the same settings as used for the series.

Section thickness was estimated for each series by counting the number of sections spanned by longitudinally sectioned mitochondria in single sections. The diameter of a mitochondrion was measured on a calibrated section image. Because mitochondria are cylindrical, section thickness could be estimated for each mitochondrion using: thickness (micrometers per section $)=$ measured diameter divided by the number of sections spanned. The mean section thickness for each series was obtained by averaging the results from 22-25 mitochondria distributed evenly through the series.

Objects in aligned and calibrated series were measured and traced using IGL Trace, a Windows software application also developed in the IGL. 3D surface reconstructions of particular objects were generated in VRML format by IGL Trace and then imported into 3D Studio MAX (Autodesk Inc., San Rafael, CA) using Keith Rule's Crossroads program (http://www.europa.com/ keithr/). For production of figures, micrographs were scanned at 600 dpi with the ScanJet 4c. Rendered 3D images and scanned EMs were combined and annotated with Photo-Paint 7 (Corel Corp., Ottawa, Ontario, Canada).

\section{RESULTS}

Electron micrographs from 1-12-d-old animals exhibited varying amounts of extracellular space (Figs. 1-4). Extracellular space appeared to decrease with age until by day 12 there was very little extracellular space, as in adult hippocampus. The neuropil contained numerous axonal and dendritic profiles, many with well ordered, often densely packed microtubules at all ages. The density of these profiles increased with age while their average diameter decreased, suggesting an increasingly fine arborization of both dendritic and axonal processes over the first two postnatal weeks.

Some dendrites in most (but not all) series exhibited enlargements with less dense cytoplasm and disorganized, sparsely distributed microtubules (Fig. 3). These enlargements were spherical to fusiform in shape and up to $3 \mu \mathrm{m}$ in diameter. They were separated along the length of a dendrite by much thinner regions with well ordered microtubule arrays. These varicosities gave the dendrites a beaded appearance consistent with that observed in other developmental studies (Schwartz et al., 1968; Morest, 1969a; Pokorny and Yamamoto, 1981). Many varicosities had the appearance of being swollen as evidenced by watery cytoplasm, few organelles, and the presence of clear vacuoles, but mitochondria were consistently small and dense, exhibiting no signs of swelling in all dendrites and axons.

Synapses were identifiable at all ages by the presence of spherical vesicles $30-40 \mathrm{~nm}$ in diameter clustered near a darkly 


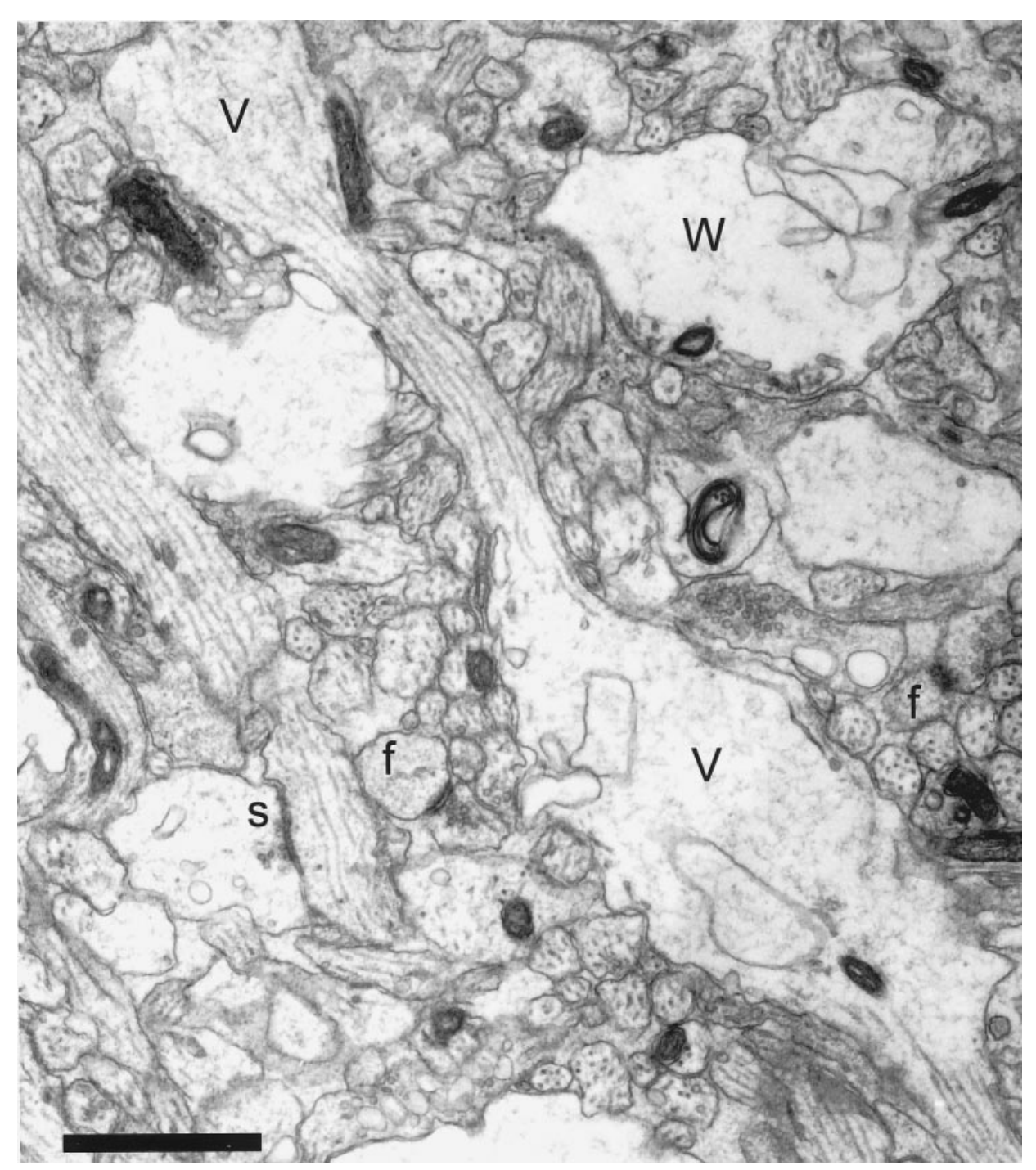

Figure 3. Neuropil from postnatal day 6 (R43b) showing varicosities $(V)$ with interposed thin regions that give some dendrites a beaded appearance. Some varicosities had a watery cytoplasm $(W)$ with organelles compressed to the periphery, suggesting that they might have undergone swelling. A synapse $(s)$ located on a dendritic shaft has the appearance of a symmetric synapse with equally thin densities on both membranes. Asymmetric synaptic contacts on two dendritic filopodia profiles $(f)$ were identified through serial sections. Note that these profiles might be mistaken for dendritic spines if they were viewed only on this section. Scale bar, $1 \mu \mathrm{m}$.

stained, paramembranous density (Figs. 1-4). Most synapses had the typical appearance of asymmetric excitatory contacts, with a presynaptic cluster of vesicles apposed to a PSD. Occasionally, symmetric synapses were observed with a thinner PSD that was matched by an equal density on the presynaptic side (Fig. 3). In the first postnatal week there were many small asymmetric synaptic contacts with just a few synaptic vesicles, some of which were in close proximity to the presynaptic membrane, suggesting that they were docked at presynaptic release sites and that the synapses were functional (Fig. 2). In addition, there were numerous cell-cell contacts with small paramembranous densities without any synaptic vesicles. These apparently nonsynaptic surface specializations had densities at one or both of the apposed cell membranes (Fig. 1).

Numerous processes having characteristics consistent with those of dendritic filopodia (Morest, 1969b; Ulfhake and Cullheim, 1988; Papa et al., 1995; Dailey and Smith, 1996; Ziv and Smith, 1996; Collin et al., 1997) were observed in developing area CA1. These filopodia emerged primarily from dendritic shafts with well organized microtubule arrays (Figs. 1, 2), rather than from growth cones of dendrite terminals (Vaughn, 1989). Dendritic filopodia were devoid of microtubules and other organelles, although sometimes thin, clear tubules or vesicles were seen. The cytoplasm was dark and grainy, consistent with a dense actin matrix (Markham and Fifkova, 1986).

Dendritic filopodia differed in appearance from dendritic spines, lacking bulbous heads with single synaptic contacts and thin necks, as in adult spines. Dendritic filopodia were longer than typical adult spines and had a pointy tip, frequently without a synapse (Figs. 2, 5). Most dendritic filopodia were irregularly cylindrical in shape. The cross-sectional diameter was variable, but usually $0.1-0.4 \mu \mathrm{m}$ (Figs. 1, 2). Along the length of a single filopodium the diameter could vary by an order of magnitude (Fig. 5). In single sections it was impossible to distinguish crosssections of filopodia from cross-sections of dendritic spines (Fig. 3 ), instead dendritic filopodia were accurately identified by tracing their entire length through serial sections.

Dendritic filopodia were observed at all ages but most frequently during the first postnatal week. By P12, many actin-filled dendritic processes had the shape of adult spines with a bulbous head and a thin neck (Fig. 4). However, these early spines often exhibited characteristics not typical of adult spines. Some atypical spines had darker cytoplasm than adult spines stained by the same protocol (Harris et al., 1992; Spacek and Harris, 1997). Many atypical spines had multiple synaptic contacts from different axons. In some cases it was difficult to distinguish a filopodium from 


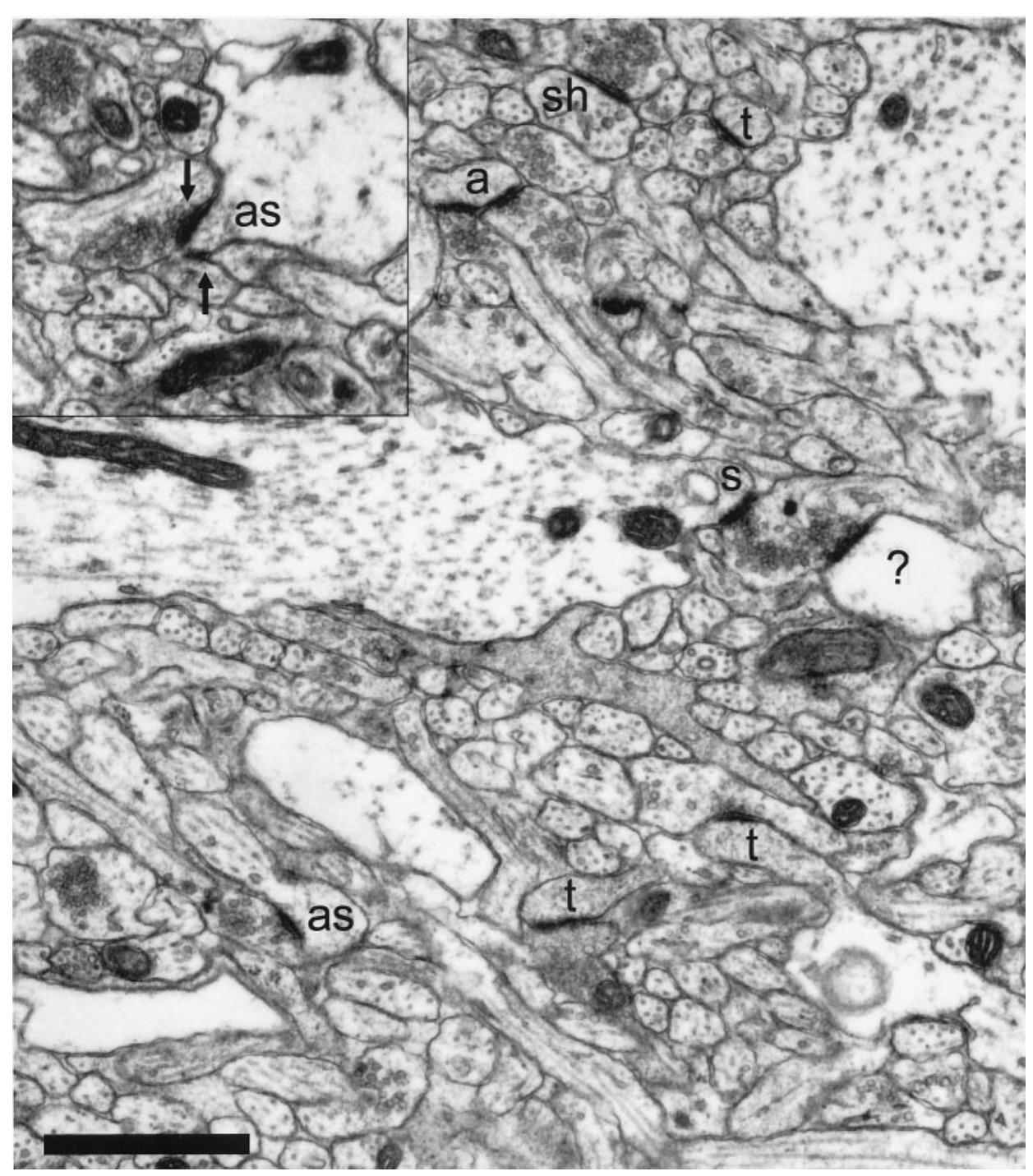

Figure 4. The neuropil from postnatal day 12 (R45a) is much denser than in the first postnatal week, with many more profiles of small processes. Asymmetric synapses are seen on thin dendritic spines $(t)$, as well as on stubby spines $(s)$ and dendritic shafts $(s h)$. Many dendritic spines at this age do not have the typical characteristics of adult CA1 spines. An atypical thin spine $(a)$ receives synaptic contacts from two different axons. Multiple synapses are rarely identifiable on single sections. The atypical stubby (as) in the lower left has only one of its two synapses visible on this section, whereas two synapses (arrows) are apparent on the atypical stubby (as) in the inset. One postsynaptic process (?) could not be traced to its origin and, therefore, could not be unequivocally identified. Scale bar, $1 \mu \mathrm{m}$. an atypical spine (Fig. 6). Such processes had a bulbous head with a very long neck, similar in appearance to the "torturous spines" observed in some forms of mental retardation (Purpura, 1975).

A few microtubule-free, actin-filled processes exhibited a complex, noncylindrical shape. These were often sheet-like or of large diameter extending through large volumes with subprocesses and holes, consistent with the ultrastructural appearance of growth cones and lamellipodia (Pappas et al., 1975; Pfenninger and Rees, 1976). Structures with some of these characteristics protruded from dendrite shafts, giving the appearance of an emerging dendritic branch (Fig. 7). The difference between these apparent growth structures and the thinner filopodia, taken in conjunction with observations in cultured cells (cf. Dailey and Smith, 1996), suggests that most dendritic filopodia are not nascent branches of the dendritic arborization.

Axonal filopodia were sometimes similar in appearance to dendritic filopodia (Fig. 1) but were more often broader and shorter extensions from the axon (Figs. 5, 8). These axonal filopodia were observed in contact with dendritic filopodia. Dendritic filopodia received asymmetric synaptic contacts and often displayed nonsynaptic surface specializations where they contacted other elements of the neuropil, especially at their tips. Axonal filopodia, on the other hand, contained synaptic vesicles and sometimes appeared to participate in the formation of nascent synapses, particularly at points of contact with dendritic filopodia (Figs. 1, 5, 8).

Synapses were found at the base and along the length of dendritic filopodia (Fig. 9). Often a single filopodium exhibited multiple synapses along its length, up to six were observed. Dendritic filopodia without synapses were also observed, particularly during the first postnatal week, but these were not quantified.

To assess the overall distribution of synapses in area CA1 during development, volumes of tissue containing 50-120 synapses were analyzed (Materials and Methods). In total, more than $6500 \mu \mathrm{m}^{3}$ were systematically analyzed revealing a total of 1483 synapses (Table 1). Approximately $4.5 \%$ of these synapses were unidentified, the rest were classified according to synapse type and location. Synapses on growth cones/lamellipodia and symmetric synapses comprised only 2.8 and $1.3 \%$, respectively, of synaptic contacts across all ages and so are not shown in the figures. During the first postnatal week, $21 \pm 6.0 \%$ of 1062 identified synaptic contacts in area CA1 occurred on filopodia, whereas $75 \%$ of the synapses occurred on shafts, stubbies, or spines (Fig. 10).

Synaptic filopodia identified in the volume analysis that could 


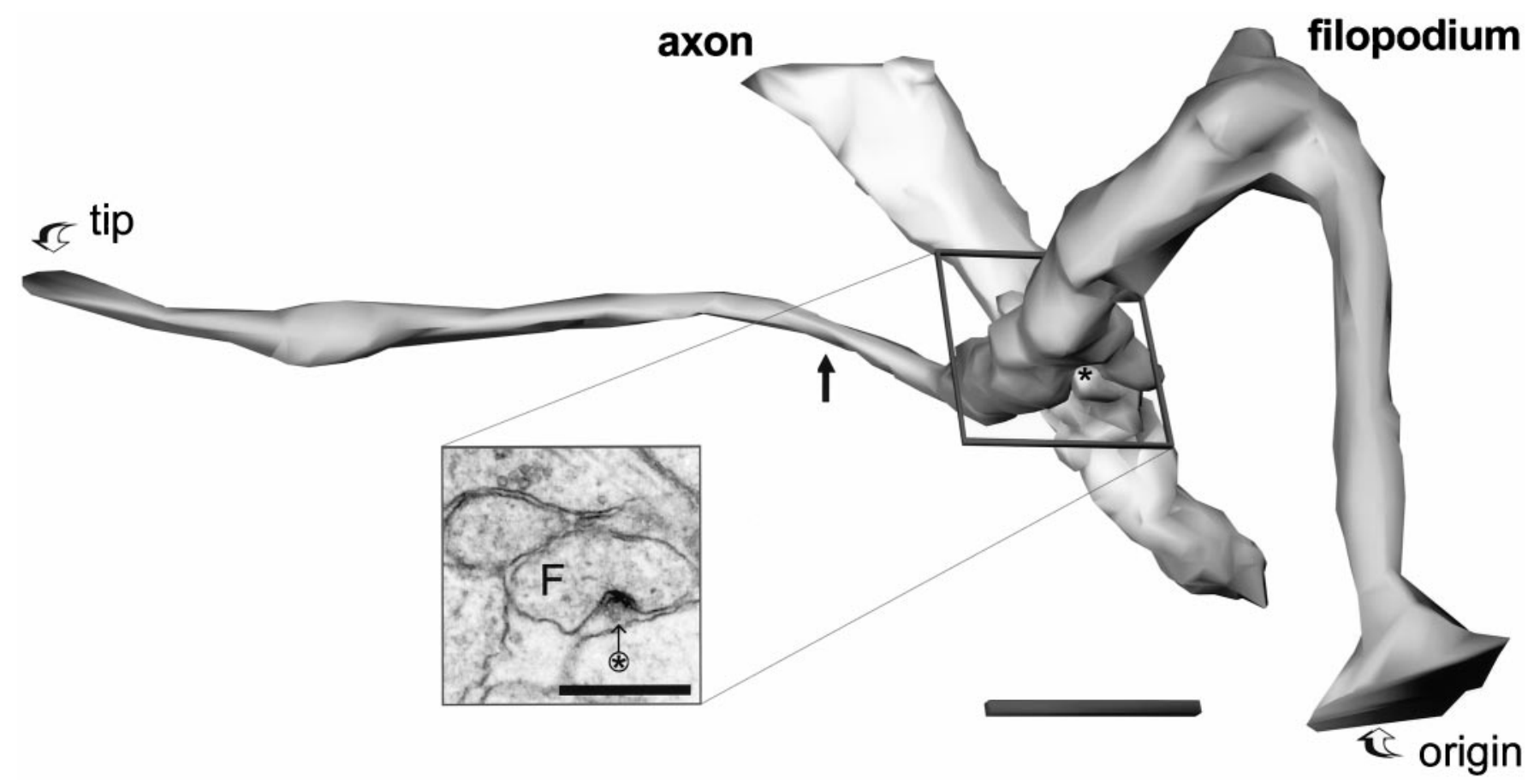

Figure 5. Three-dimensional reconstruction of the dendritic filopodium whose origin is shown in Figure 2. The filopodium is $\sim 11 \mu \mathrm{m}$ long from origin to tip. Filopodia of this length were rarely captured in series of only 100 ultrathin sections. At its narrowest point (solid arrow) the filopodium has a diameter of $\sim 0.1 \mu \mathrm{m}$, whereas the maximum diameter is $\sim 1 \mu \mathrm{m}$. The filopodium is enfolded in stubby protrusions from the axon, one of which (star) appears to make a synaptic contact with the filopodium $(F)$ (inset, star arrow). Scale bar in inset, $0.5 \mu \mathrm{m} ; 3 \mathrm{D}$ scale bar, $1 \mu \mathrm{m}$.

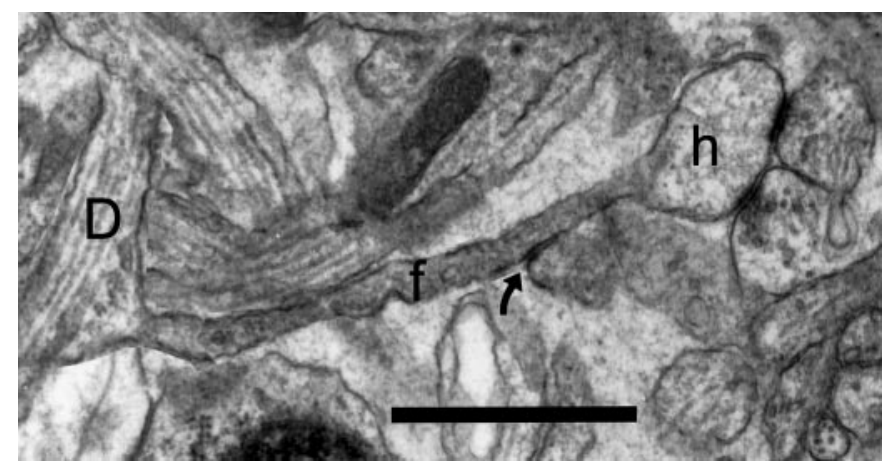

Figure 6. A montage of four sections from postnatal day 6 (R44a) showing a filopodium $(f)$ emerging from a dendrite $(D)$, and terminating in a bulbous head $(h)$ that has two synapses from different axons. The filopodium is similar in shape to an atypical spine (see Materials and Methods), but its unusual length $(\sim 3 \mu \mathrm{m})$ is more characteristic of a filopodium. In addition, the "neck" has a variable diameter, a dark cytoplasm suggesting a dense accumulation of actin, and exhibits a surface specialization at one point along its length where it contacts another dendritic process (arrow). Scale bar, $1 \mu \mathrm{m}$.

be traced in entirety from origin to distal tip were further analyzed to determine the distribution of synapses along the filopodia (Fig. 11). There were 162 completely traceable dendritic filopodia across all ages. These 162 filopodia received a total of 255 synaptic contacts. Most filopodia had only one synapse, but $41 \%$ had multiple synapses from different presynaptic partners. Unlike spines, which have synapses preferentially located on the spine head, filopodia can have synapses anywhere with equal probability. Of the 162 complete filopodia, 65 had at least one synapse at the tip, 74 had at least one synapse at the base, and 76 had at least one synapse in an intermediate location between the tip and base. Of the 255 filopodial synapses, 80 were at the tip, 83 were at the base, and 92 were found in an intermediate location. There was a trend for synapses to be located more on the tips of filopodia at P12 (Fig. 11).

Synapses on filopodia occurred at enlargements or swellings in filopodia. Although synaptic swellings in filopodia were occasionally bulbous like spine heads (Fig. 6), more often they were fusiform in shape (Fig. 9). Often multiple synapses were observed on a single filopodial enlargement. Among the 80 tip synapses on the 162 complete filopodia, $81 \%$ occurred on these enlargements. Similarly, $77 \%$ of the mid synapses occurred on identified enlargements in filopodia. In total, only $21 \%$ of tip and mid synapses were not located on enlargements.

Filopodia usually occurred as single processes, but sometimes they were branched or several emerged in a clump (Fig. 9). Approximately $9.3 \%$ of the filopodia identified through the synapse analysis had a branched morphology. Filopodia originated from dendrites of all sizes. Of those origins that could be clearly classified, $23 \%$ were large, apical-like dendrites with well organized microtubules, whereas $34 \%$ were thin dendrites with well organized microtubules. The remaining filopodia (43\%) originated from varicose regions of dendrites (Fig. 9).

The distribution of synapse locations in CA1 changed with developmental age (Fig. 12). Synapses were found mostly on dendritic shafts during the first postnatal week. Asymmetric shaft synapses were also frequent at P12. There was a statistically significant increase in the frequency of spine synapses with age $\left(F_{(3,12)}=16.30 ; p<0.0002\right)$. At P1 $4.9 \pm 4.3 \%$ of synapses were on dendritic spine-like protrusions. These $\mathrm{P} 1$ spines all had characteristics that were not typically found in adult spines, suggesting that they might be retracting filopodia rather than true spines. By P12 the proportion of spine synapses had risen to $37 \pm 14 \%$ of all synapses. This increase in spine synapses was accompanied 


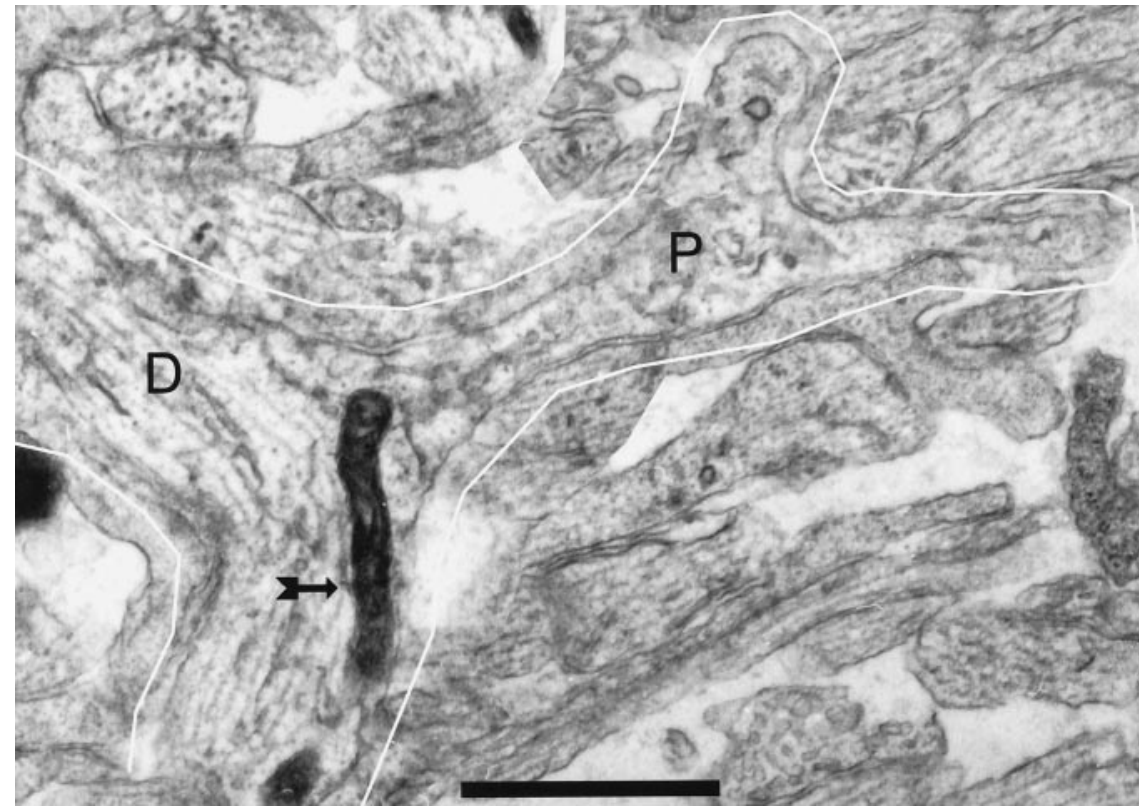

Figure 7. A montage of two sections from P1 (R55) showing a vesicle-filled process $(P)$ emerging from a bend in a dendrite $(D)$, all of which is outlined in white. This process shares more characteristics with growth processes than most dendritic filopodia (compare with Figs. 1 and 2), suggesting that it might represent a budding branch of the dendrite. Note the mitochondrian (arrow) partly invades the base of the process. Mitochondria were never observed in filopodia. Scale bar, $1 \mu \mathrm{m}$. by a decrease in filopodial $\left(F_{(3,12)}=4.82 ; p<0.02\right)$ and shaft $\left(F_{(3,12)}=3.97 ; p<0.036\right)$ synapses. By P12, filopodial synapses were only $7.2 \pm 4.7 \%$ of all synapses.

\section{DISCUSSION}

Recent studies have demonstrated dynamic dendritic filopodia in the early development of area CA1 in vitro (Dailey and Smith, 1996; Ziv and Smith, 1996; Collin et al., 1997). Their movements and interactions with other elements in the culture suggest that they may be involved in locating presynaptic targets and consolidating them into stable synapses. As a consequence, Dailey and Smith (1996) proposed that dendritic filopodia are involved in the establishment of all axodendritic synapses in hippocampal area CA1. However, evidence for large numbers of synapses on filopodia has been lacking (Markham and Fifkova, 1986; Harris et al., 1992; Papa et al., 1995). One reason may have been the limitations of single-section analyses in differentiating filopodial synapses from stubby or spine head synapses (Schwartz et al., 1968; Steward and Falk, 1991; compare Fig. 3). The serial section analyses of the present work provide evidence that enough synaptic contacts occur on dendritic filopodia in vivo to support the Dailey and Smith (1996) proposal.

In fact, there appear to be far more filopodial synapses than are consolidated into synapses of other types. From Table 1 it can be seen that there were, on average, 3.1 filopodial synapses $/ 100 \mu \mathrm{m}^{3}$ at P4 and 6.2/100 $\mu \mathrm{m}^{3}$ at P6. Ziv and Smith (1996) report the average lifetime of a filopodium is about $10 \mathrm{~min}$ in vitro. A more conservative assumption would be that the entire population of filopodia turns over once an hour, giving an average of 4.65 new filopodial synapses $/ 100 \mu \mathrm{m}^{3} / \mathrm{hr}$. In $48 \mathrm{hr}, 223 / 100 \mu \mathrm{m}^{3}$ new synapses should have been created by a filopodial synaptogenic mechanism. Only $14.6 / 100 \mu \mathrm{m}^{3}$ nonfilopodial synapses were created between P4 and P6 (Table 1). Thus, probably $<7 \%$ of filopodial synapses were retained during this period.

A long-standing hypothesis for the formation of spine synapses in hippocampus is that spines arise from shaft synapses by a process of outgrowth (Cotman et al., 1973; Pokorny and Yamamoto, 1981). This idea has been supported by the repeated finding that shaft synapses predominate early in the development of hippocampus (Cotman et al., 1973; Pokorny and Yamamoto, 1981; Schwartzkroin et al., 1982; Steward and Falk, 1991; Harris et al., 1992; Boyer et al., 1998) and in other brain regions as well (Juraska and Fifkova, 1979; Miller and Peters, 1981; Mates and Lund, 1983; Landis, 1987). The results of the present study also show that most synapses occur on dendritic shafts during the first two postnatal weeks. The density of shaft synapses does not decrease until the later stages of development (P15 to adult), during the transition to the full complement of spines (Harris et al., 1992). This, along with the appearance of synapses on stubby protrusions intermediate between shafts and spines, suggests that spines arise from shaft synapses by a process of outgrowth. Dynamic outgrowth of mature-looking spines from dendritic shafts has also been observed in culture (Dailey and Smith, 1996).

If filopodia give rise to all synapses as proposed by Dailey and Smith (1996), then filopodia frequently give rise to shaft synapses, because these predominate during the first postnatal week. To compare the likelihood of shaft and stubby synapse creation to spine synapse creation, consider the data of Table 1. There were 4.9 spine synapses $/ 100 \mu \mathrm{m}^{3}$ created between $\mathrm{P} 4$ and $\mathrm{P} 6$, whereas the combined increase in shaft and stubby synapses was $8.0 / 100$ $\mu \mathrm{m}^{3}$ during this same period. Thus, less than half of new synapses are of the spine type. Spine synapses created directly from filopodia may be an even smaller portion of new synapses, however, if we consider the possibility that some spines may be forming from shaft synapse outgrowth during this period.

A significant proportion of spines identified in the present material exhibited multiple synaptic contacts and other irregularities distinguishing them from adult spines in area CA1. These atypical spines might be related to the "protospines" of Dailey and Smith (1996), which were observed to be persistent but still showed structural changes. Atypical spines might also be filopodia in the process of retracting. In either case they will undergo further development in which competing synapses are eliminated, but it is not clear whether they ultimately remain spines or whether they experience an intermediate shaft stage. If atypical spines are not true spines, then they should be excluded from the estimate of new spine synapses. This yields only $1.8 / 100 \mu \mathrm{m}^{3}$ new 

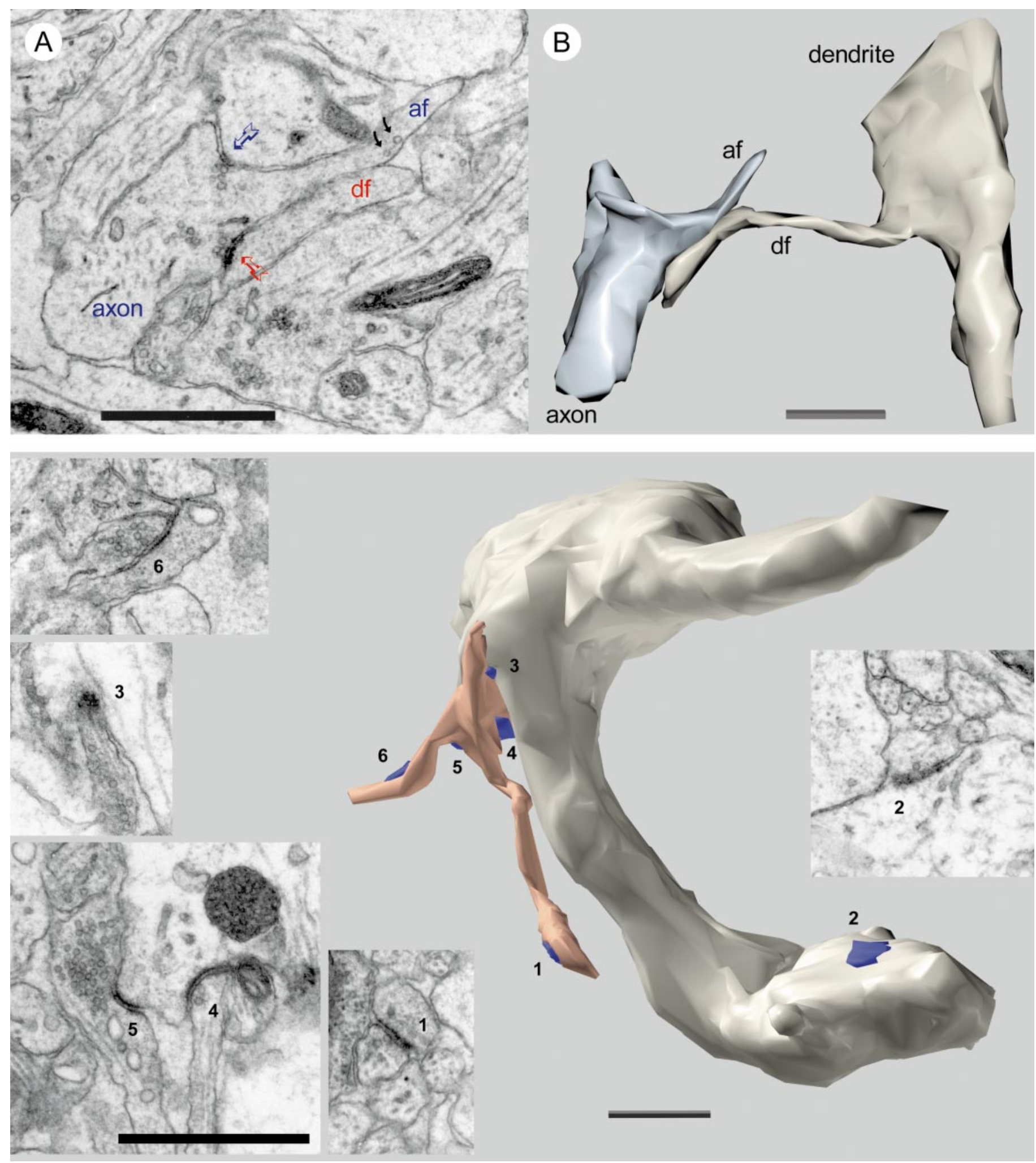

Figure 8. Top. Interaction between axonal and dendritic filopodia at postnatal day 4 (R48a). A, An axon has a broad protrusion with a grainy cytoplasm indicative of actin. This actin-filled region is devoid of microtubules and ends in a narrow process (af) identical in appearance to dendritic filopodia except for the presence of synaptic vesicles (black arrows). There are two synapses at the base of this axonal filopodium, one (blue arrow) with a dendrite shaft and another (red arrow) with the tip of a dendritic filopodium $(d f)$. B, Three-dimensional reconstruction of segments of the same axon and dendrite with the interacting filopodia that are shown in $A$. Scale bars, $1 \mu \mathrm{m}$.

Figure 9. Bottom. A cluster of filopodia emerging from a varicosity in a beaded dendrite at P6 (R43a). Reconstruction of a segment of the dendrite shows the location of six synapses (blue). The filopodia (copper) receive synaptic contacts near the tips $(1,6)$ and at the base $(3,4,5)$. An additional shaft synapse (2) can be seen on the surface of the dendrite. Two other shaft synapses and one spine synapse (data not shown) also occurred on this dendritic segment. Electron micrographs (insets) show the details of each synapse. Scale bars in insets, $0.5 \mu \mathrm{m}$; 3D scale bar, $1 \mu \mathrm{m}$. 


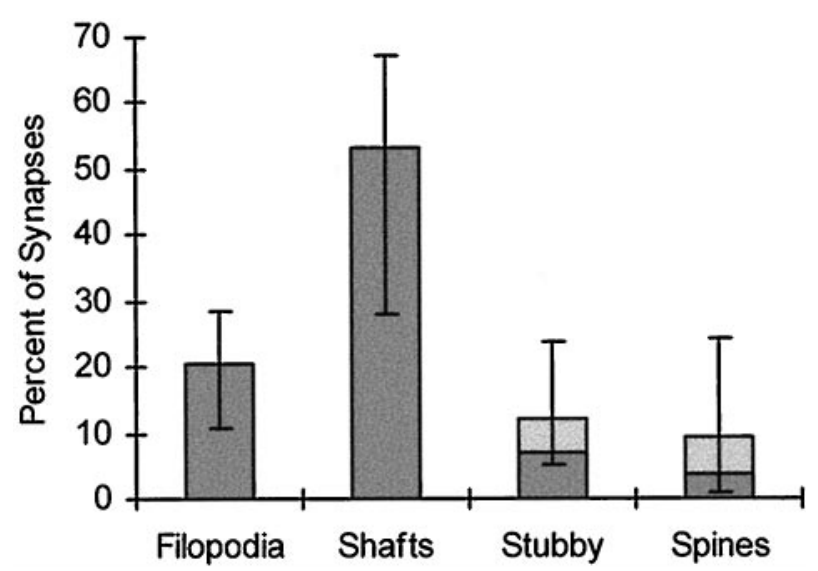

Figure 10. Distribution of synapse locations in CA1 during the first postnatal week. Bars represent the mean percentages of synapses in each class. Light shading indicates mean percentages for atypical spines and stubbies (see Materials and Methods for details). Error bars show the minimum and maximum values for combined means measured in 12 series from seven animals aged P1, P4, and P6.

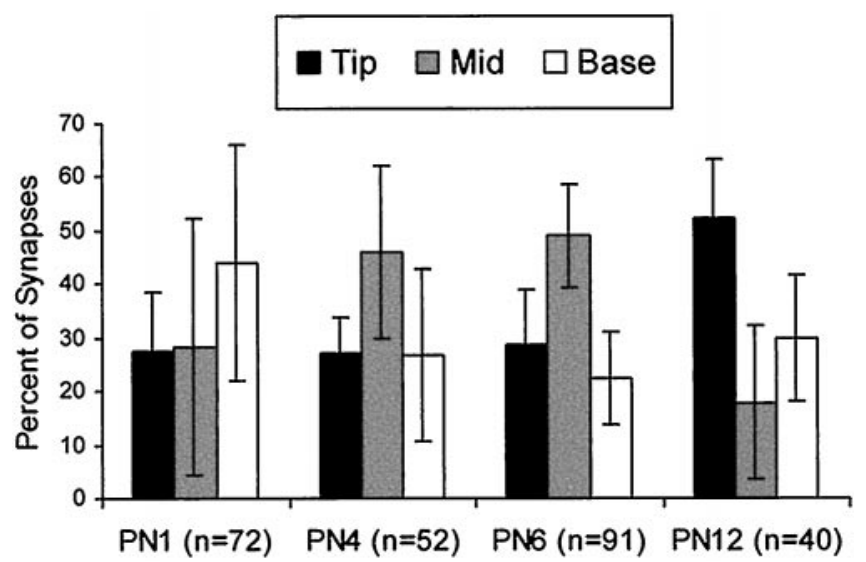

Figure 11. The location of synapses on 162 complete filopodia as a percent of the total number $(n)$ of synapses on these filopodia at each age. There were more tip locations at $\mathrm{P} 12\left(F_{(3,12)}=6.21 ; p<0.009\right)$, but apparent trends in mid and base locations were not statistically significant $(p<0.07$ and $p<0.26$, respectively).

spine synapses from P4 to P6, versus 6.9/100 $\mu \mathrm{m}^{3}$ for shafts alone. Thus, far fewer stable spine synapses than shaft synapses appear to be created from filopodia during the early stages of synaptogenesis.

It is well established that spiny neurons exhibit dendritic filopodia during developmental synaptogenesis. This has been reported for visual cortex (Lund et al., 1977; Miller and Peters, 1981; Markham and Fifkova, 1986), cerebellar cortex (Berry et al., 1972), red nucleus (Saito et al., 1997), and many other areas (Morest, 1969b). But even neurons that are nonspiny when mature exhibit dendritic filopodia during synaptogenesis (Lund et al., 1977; Difiglia et al., 1980; Dvergsten et al., 1986; Ulfhake and Cullheim, 1988; Wong et al., 1992; Linke et al., 1994). This finding suggests that the purpose of dendritic filopodia is not to form spines, but rather to facilitate the establishment of shaft synapses. This idea is supported by our observations and those of others (Ulfhake and Cullheim, 1988) that synapses are frequently found around the bases of filopodia.

Taken together, these observations suggest that dendritic filop-
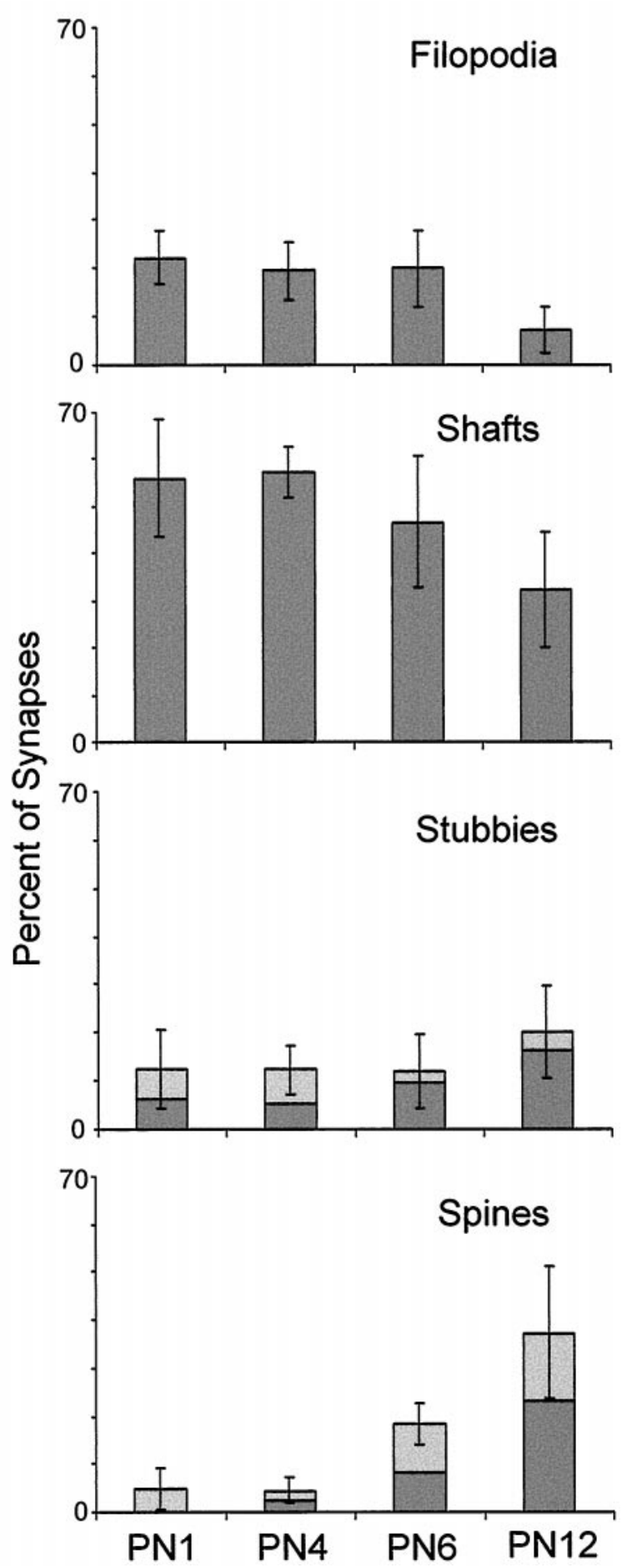

Figure 12. Distribution of synapse locations by age as revealed by the mean percentage of synapses at each location. Light regions depict percentages with atypical characteristics, (see Materials and Methods for details). Error bars indicate SDs.

odia participate in the recruitment of shaft synapses much more frequently than in the formation of mature spines. How could filopodia generate shaft synapses? One possibility is that filopodia represent a specialized receptive surface for the formation of new synapses. Synapses can form on this surface at points of contact with axons, but only contacts near the base of filopodia are 


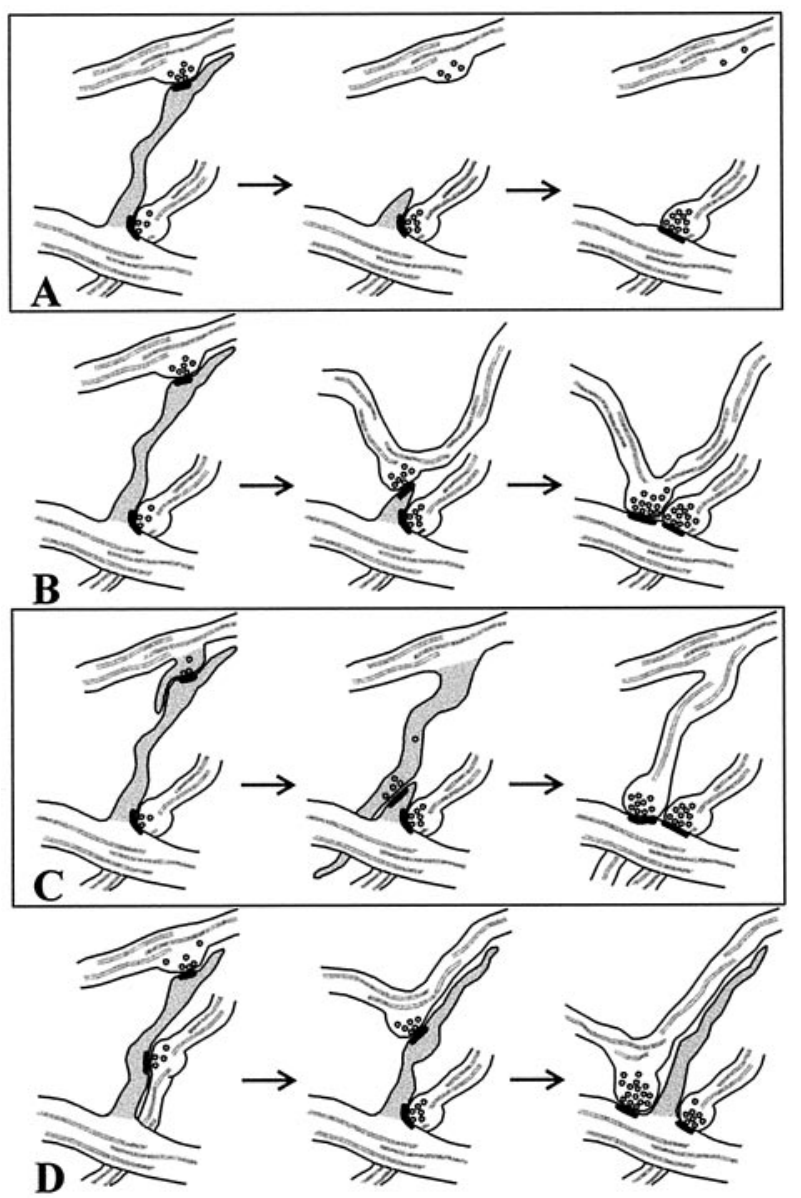

Figure 13. Possible mechanisms by which filopodia might induce shaft synapses. $A$, Synapses form on the receptive surface of filopodia, but only those near the base of filopodia are stabilized into shaft synapses. $B$, Filopodia retract, pulling the presynaptic partner to the dendrite. $C$, Dendritic filopodia guide axonal filopodia to the dendrite where synapses are stabilized by subsequent maturation of the axonal filopodium into an axon branch. $D$, Dendritic filopodia act as conduits along which synapses move to the dendrite shaft.

stabilized into shaft synapses. Synapses at the tip and along the length of filopodia are not retained (Fig. 13A).

A second possibility for the production of shaft synapses by filopodia is that filopodia make a nascent synapse at their tip, then retract to the dendritic shaft, pulling the presynaptic axon along with them (Fig. 13B). Several presynaptic axons could be retrieved to the shaft by the filopodium repeatedly extending and retracting. Repeated extensions and retractions of a single filopodium have been observed in vitro (Dailey and Smith, 1996; Ziv and Smith, 1996). A consequence of this mechanism is that some axons will be required to translate several micrometers through the neuropil. Competing interactions on one axon by filopodia from different dendrites would presumably cause the axon to be bent into complex undulations during early development. Later, as dendritic spines extend, the undulations could "relax" into straighter axons as seen in adults (Shepherd and Harris, 1998).

A third mechanism is suggested by the analysis of growth cone-target cell interactions in culture (Cooper and Smith, 1992; Davenport et al., 1996). These experiments show that filopodia of axonal growth cones, which contact target cell filopodia, adhere to them and grow along them to reach the cell surface. Our results
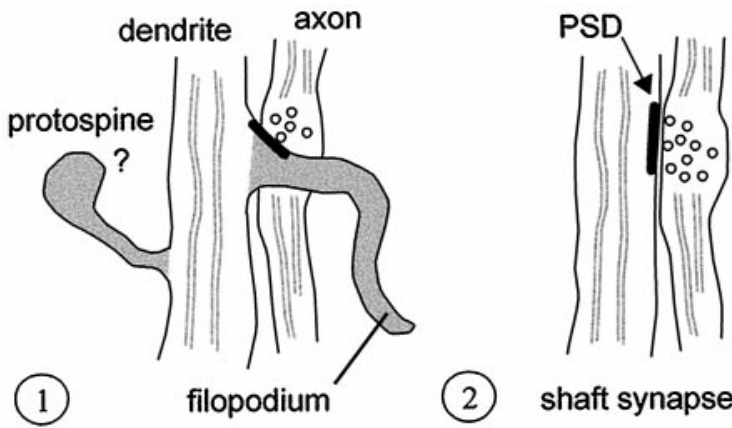

shaft synapse
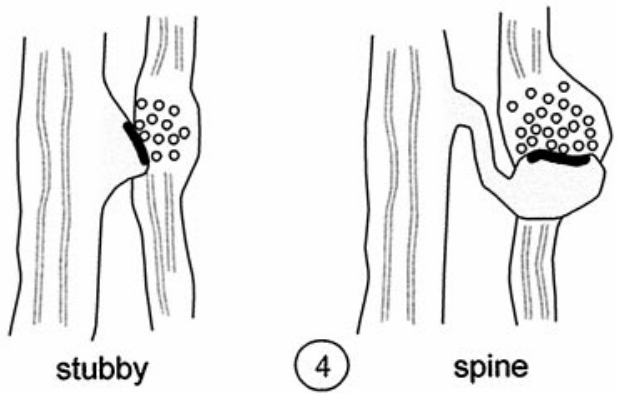

Figure 14. Genesis of most excitatory synapses may involve four stages. 1, Initial induction of a synapse by a filopodium. In early stages of development, atypical or "protospines" are apparent, but their ultimate fate is unclear. 2, Retraction of the filopodia and stabilization of the synapse on the dendrite shaft. 3, Emergence of a stubby protrusion beneath the synapse. 4 , Outgrowth of protrusion into a mature spine.

similarly show axonal filopodia contacting dendritic filopodia and in some cases extending along their length (Fig. 8). So shaft synapses might arise from direct axon-dendrite contacts produced as a result of the axonal branching and growth along dendritic filopodia (Fig. 13C). This idea is supported by studies showing that axon terminal arborizations can exhibit dynamic filopodia (O'Rourke et al., 1994), but not every synapse on a dendritic filopodium has an axonal filopodium as the presynaptic element. Perhaps, either the axonal filopodium or the dendritic filopodium could elaborate into a new lateral branch if conditions support the stabilization of the initial synaptic contact (Morest, 1969a). Dailey and Smith (1996) noted that some dendritic filopodia transform into growth cones and nascent dendrite branches. In addition, Kossel et al. (1997) have shown that increased dendritic arborization is induced by the presence of synaptic axons in culture.

The distribution of synapses all along a filopodium suggests that filopodia might act as nonretracting conduits for the transference of synaptic contacts to the dendrite shaft. The movement of actin filaments within the filopodium, which is responsible for the extension and retraction of these processes (Fisher et al., 1988; Smith, 1988; Sheetz et al., 1992), can also serve to move an attached membrane component along the filopodium (Smith, 1994). Thus, nascent synapses forming near the filopodium tip could be transported down the filopodium to eventually mature into shaft synapses (Fig. 13D). This mechanism also requires axons to translocate as the synapse is pulled to the dendrite.

In conclusion, the results show that dendritic filopodia are involved in developmental synaptogenesis in area CA1, making nascent synaptic contacts with axonal elements. Although some filopodia appear to retract into atypical or "protospines", filopodia result in mostly shaft synapses by an unknown mechanism (Fig. 14). While it is possible that these early shaft synapses are 
not the source of spine synapses (Landis, 1987), our current knowledge favors a model in which these shaft synapses are subsequently converted to dendritic spines.

\section{REFERENCES}

Berry M, Hollingworth T, Flinn RM, Anderson EM (1972) The growth of Purkinje cell dendrites of the rat - a quantitative study. J Anat 111:491-493.

Boyer C, Schikorski T, Stevens CF (1998) Comparison of hippocampal dendritic spines in culture and in brain. J Neurosci 18:5294-5300.

Collin C, Miyaguchi K, Segal M (1997) Dendritic spine density and LTP induction in cultured hippocampal slices. J Neurophysiol 77:1614-1623.

Cooper MW, Smith SJ (1992) A real-time analysis of growth cone-target cell interactions during the formation of stable contacts between hippocampal neurons in culture. J Neurobiol 23:814-828.

Cotman C, Taylor D, Lynch G (1973) Ultrastructural changes in synapses in the dentate gyrus of the rat during development. Brain Res 63:205-213.

Dailey ME, Smith SJ (1996) The dynamics of dendritic structure in developing hippocampal slices. J Neurosci 16:2983-2994.

Davenport RW, Dou P, Mills LR, Kater SB (1996) Distinct calcium signaling within neuronal growth cones and filopodia. J Neurobiol 31:1-15.

Difiglia M, Pasik P, Pasik T (1980) Early postnatal development of the monkey neostriatum: a Golgi and ultrastructural study. J Comp Neurol 190:303-331.

Dvergsten CL, Hull CD, Levine MS, Adinolfi AM, Buchwald NA (1986) Postnatal differentiation and growth of cat entopeduncular neurons. A transient spiny period associated with branch elongation. Brain Res 389:239-251.

Fisher GW, Conrad PA, DeBiasio RL, Taylor DL (1988) Centripetal transport of cytoplasm, actin, and the cell surface in lamellipodia of fibroblasts. Cell Motil Cytoskeleton 11:235-247.

Galofre E, Ferrer I, Fabregues I, Lopez-Tejero D (1987) Effects of prenatal ethanol exposure on dendritic spines of layer $\mathrm{V}$ pyramidal neurons in the somatosensory cortex of the rat. J Neurol Sci 81:185-195.

Harris KM, Kater SB (1994) Dendritic spines: cellular specializations imparting both stability and flexibility to synaptic function. Annu Rev Neurosci 17:341-371.

Harris KM, Jensen FE, Tsao B (1992) Three-dimensional structure of dendritic spines and synapses in rat hippocampus (CA1) at postnatal day 15 and adult ages: implications for the maturation of synaptic physiology and long-term potentiation. J Neurosci 12:2685-2705.

Juraska JM, Fifkova E (1979) An electron microscope study of the early postnatal development of the visual cortex of the hooded rat. J Comp Neurol 183:257-268.

Kossel AH, Williams CV, Schweizer M, Kater SB (1997) Afferent innervation influences the development of dendritic branches and spines via both activity-dependent and non-activity-dependent mechanisms. J Neurosci 17:6314-6324.

Landis DMD (1987) Initial junctions between developing parallel fibers and Purkinje cells are different from mature synaptic junctions. J Comp Neurol 260:513-525.

Linke R, Soriano E, Frotscher M (1994) Transient dendritic appendages on differentiating septohippocampal neurons are not the sites of synaptogenesis. Dev Brain Res 83:67-78.

Lund JS, Boothe RG, Lund RD (1977) Development of neurons in the visual cortex (area 17) of the monkey (Macaca nemestrina): a Golgi study from fetal day 127 to postnatal maturity. J Comp Neurol 176:149-188.

Marin-Padilla M (1972) Structural abnormalities of the cerebral cortex in human chromosomal aberrations: a Golgi study. Brain Res 44:625-629.

Markham JA, Fifkova E (1986) Actin filament organization within dendrites and dendritic spines during development. Dev Brain Res 27:263-269.

Mates SL, Lund JS (1983) Spine formation and maturation of type 1 synapses on spiny stellate neurons in primate visual cortex. J Comp Neurol 221:91-97.

Miller M, Peters A (1981) Maturation of rat visual cortex. II. A combined Golgi-electron microscope study of pyramidal cells. J Comp Neurol 203:555-573.
Morest DK (1969a) The differentiation of cerebral dendrites: a study of the post-migratory neuroblast in the medial nucleus of the trapezoid body. Z Anat Entwicklungsgesch 128:271-289.

Morest DK (1969b) The growth of dendrites in the mammalian brain. Z Anat Entwicklungsgesch 128:290-317.

O'Rourke NA, Cline HT, Fraser SE (1994) Rapid remodeling of retinal arbors in the tectum with and without blockade of synaptic transmission. Neuron 12:921-934.

Papa M, Bundman MC, Greenberger V, Segal M (1995) Morphological analysis of dendritic spine development in primary cultures of hippocampal neurons. J Neurosci 15:1-11.

Pappas GD, Fox GQ, Masurovsky EB, Peterson ER, Crain SM (1975) Neuronal growth cone relationships and their role in synaptogenesis in the mammalian central nervous system. In: Advances in Neurology, Vol 12 (Kreutzberg GW, ed), pp 163-180. New York: Raven.

Peters A, Kaiserman-Abramof IR (1970) The small pyramidal neuron of the rat cerebral cortex: the perikaryon, dendrites and spines. J Anat 127:321-356.

Pfenninger KH, Rees RP (1976) From growth cone to the synapse: properties of membranes involved in synapse formation. In: Neuronal recognition (Barondes SH, ed), pp 131-178. New York: Plenum.

Pokorny J, Yamamoto T (1981) Postnatal ontogenesis of hippocampal CA1 area in rats. II. Development of ultrastructure in stratum lacunosum and moleculare. Brain Res Bull 7:121-130.

Purpura DP (1975) Dendritic differentiation in human cerebral cortex: Normal and aberrant development patterns. In: Advances in neurology, Vol 12 (Kreutzberg GW, ed), pp 91-116. New York: Raven.

Saito Y, Song W-J, Murakami F (1997) Preferential termination of corticorubral axons on spine-like dendritic protrusions in developing cat. J Neurosci 17:8792-8803.

Schwartz IR, Pappas GD, Purpura DP (1968) Fine structure of neurons and synapses in the feline hippocampus during postnatal ontogenesis. Exp Neurol 22:394-407.

Schwartzkroin PA, Kunkel DD, Mathers LH (1982) Development of rabbit hippocampus: anatomy. Dev Brain Res 2:453-468.

Sheetz MP, Wayne DB, Pearlman AL (1992) Extension of filopodia by motor-dependent actin assembly. Cell Motil Cytoskeleton 22:160-169.

Shepherd GMG, Harris KM (1998) Three-dimensional structure and composition of CA3- > CA1 axons in rat hippocampal slices: implications for presynaptic connectivity and compartmentalization. J Neurosci, in press.

Smith CL (1994) Cytoskeletal movements and substrate interactions during initiation of neurite outgrowth by sympathetic neurons in vitro. J Neurosci 14:384-398.

Smith SJ (1988) Neuronal cytomechanics: the actin based motility of growth cones. Science 242:708-715.

Spacek J, Harris KM (1997) Three-dimensional organization of smooth endoplasmic reticulum in hippocampal CA1 dendrites and dendritic spines of the immature and mature rat. J Neurosci 17:190-203.

Steward O, Falk PM (1991) Selective localization of polyribosomes beneath developing synapses: A quantitative analysis of the relationships between polyribosomes and developing synapses in the hippocampus and dentate gyrus. J Comp Neurol 314:545-557.

Stoltenburg-Didinger G, Spohr HL (1983) Fetal alcohol syndrome and mental retardation: spine distribution of pyramidal cells in prenatal alcohol-exposed rat cerebral cortex: a Golgi study. Brain Res 313:119-123.

Ulfhake B, Cullheim S (1988) Postnatal development of cat hind limb motoneurons. II: In vivo morphology of dendritic growth cones and the maturation of dendrite morphology. J Comp Neurol 278:88-102.

Vaughn JE (1989) Fine structure of synaptogenesis in the vertebrate central nervous system. Synapse 3:255-285.

Wisniewski KE, Segan SM, Miezejeski CM, Sersen EA, Rudelli RD (1991) The Fra(X) syndrome: neurological, electrophysiological, and neuropathological abnormalities. Am J Med Genet 38:476-480.

Wong ROL, Yamawaki RM, Shatz CL (1992) Synaptic contacts and the transient dendritic spines of developing retinal ganglion cells. Eur J Neurosci 4:1387-1397.

Ziv NE, Smith SJ (1996) Evidence for a role of dendritic filopodia in synaptogenesis and spine formation. Neuron 17:91-102. 